\title{
Parafoveal processing of prefixed words during eye fixations in reading: Evidence against morphological influences on parafoveal preprocessing
}

\author{
GRETCHEN KAMBE \\ University of Nevada, Las Vegas, Nevada
}

\begin{abstract}
Two eye movement experiments were conducted to investigate whether the morphological constituents of a prefixed word influenced early word processing when English was read. Participants read sentences containing free-stem, bound-stem, or pseudoprefixed words, and the availability of the prefixed word morphemes in the parafovea was manipulated. Although preview benefit was greatest for the entire word, there was evidence that subsequent word processing was facilitated in both the prefix-only and the stem-only conditions. This effect was not influenced by word type. There was no evidence that morphological preprocessing occurred when morphological information was available in the parafovea. In addition, reading times for the target word did not differ for the different word types. Thus, there was no evidence to suggest that morphological constituents influence early word processing during reading. It is possible that morphological effects tend to be obscured when examined within a sentence context (although this phenomenon may be specific to English).
\end{abstract}

Many studies in which morphologically complex words have been examined have shown evidence to indicate that across a number of different languages, morphological processing is involved in the early stages of word identification (e.g., Deustch, Frost, \& Forster, 1998; Drews \& Zwisterlood, 1995; Feldman, 1994; Frost, Forster, \& Deutsch, 1997; Giraudo \& Grainger, 2000; Grainger, Cole, \& Segui, 1991; Laudanna, Badecker, \& Caramazza, 1989; Marslen-Wilson, Tyler, Waksler, \& Older, 1994). However, the majority of the research on morphological processing has focused on studies of isolated words. Very little research has been conducted on morphologically complex words during reading (although see Bertram, Hyönä, \& Laine, 2000; Hyönä \& Pollatsek, 1998; Inhoff,

The work reported here was based on a doctoral dissertation submitted to the University of Massachusetts. Portions of the data were presented at the 42nd Annual Meeting of the Psychonomic Society in Orlando, FL, 2001. The research was supported by Grants HD26765 and HD17246 from the National Institute of Health and by an NIH predoctoral fellowship on Grant HD07327. I thank the chair of my committee (Keith Rayner), the other members of the committee (Alexander Pollatsek, Marvin Daehler, and Donald Fisher), and several members of the University of Massachusetts faculty (Jerome L. Myers, Susan Duffy, and Charles Clifton, Jr.) for their support and helpful comments at all stages of the work. In addition, I thank Albrecht Inhoff and the reviewers of this manuscript for their incredibly helpful comments. Correspondence concerning this article should be addressed to G. Kambe, Department of Psychology, University of Nevada, 4505 Maryland Parkway, Box 455030, Las Vegas, NV 89154 (e-mail: gkambe@unlv.nevada.edu).

Note-This article was accepted by the previous editorial team, headed by Neil Macmillan. 1989a, 1989b; Inhoff, Briihl, \& Schwartz, 1996; Lima, 1987; Niswander, Pollatsek, \& Rayner, 2000; Pollatsek, Hyönä, \& Bertram, 2000). Thus, it is important to determine whether morphological constituents influence word processing during reading. Of particular interest is the time course of morphological processing during reading.

Because reading is a continuous process, it can be difficult to distinguish early from later stages of word processing. However, it is possible to manipulate what information is initially seen by the reader, thereby manipulating early stages of word processing. When text is read, information is acquired during eye fixations. Although the oculomotor system is especially attuned to bringing information into the fovea (the center $2^{\circ}$ of vision) for processing, parafoveal vision (the $2^{\circ}-5^{\circ}$ of vision adjacent to the fovea) also plays an important role in reading (Rayner, Well, Pollatsek, \& Bertera, 1982). By using eye-tracking technology, it is possible to (1) gain a more accurate record of reading behavior and (2) examine what types of information are being acquired and utilized in the initial stages of word processing (e.g., in the parafovea).

Research on the extent to which parafoveal information affects word processing has been concerned with the influence of information acquired in the parafovea on fixation durations during reading. The methodology typically used to study parafoveal information processing is an eyecontingent display change technique (Rayner, 1975; see Figure 1). Typically, a sentence is presented on a computer monitor. When the eyes cross a prespecified invisible boundary, some of the information on the screen changes. The display change occurs during a saccade (during which 
* I

My younger brother has brilliantly composed a new tune for the school play.

\author{
I * \\ My younger brother has brilliantly composed a new song for the school play.
}

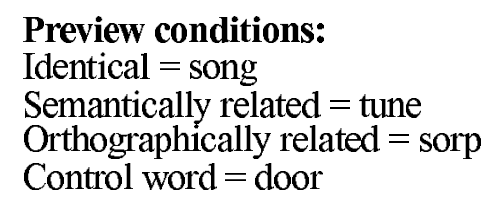

\title{
Target word: song
}

The asterisk denotes the position of the eye, and the "l" denotes the location of the boundary.

Figure 1. Example sentence (from Rayner et al., 1986) for a parafoveal preview display change experiment.

vision is suppressed, so the reader is typically unaware that it has occurred (see Binder, Pollatsek, \& Rayner, 1999; Inhoff, Starr, Liu, \& Wang, 1998). As a result, if the information presented in the parafovea affects processing when the target location is subsequently fixated (as compared with when no parafoveal information is available), it is attributed to parafoveal preview. For example, when information to the right of a fixation is degraded during reading, readers markedly decrease their reading rates (McConkie \& Rayner, 1975; Rayner \& Bertera, 1979; Rayner, Inhoff, Morrison, Slowiaczek, \& Bertera, 1981; Rayner \& Pollatsek, 1981; Rayner et al., 1982). There is now a great deal of evidence demonstrating that when readers are allowed to preview a word in the parafovea (i.e., to the right of the currently fixated word), processing time on that word when it is subsequently fixated is facilitated, in comparison with when no preview of that word is available (Balota, Pollatsek, \& Rayner, 1985; Blanchard, Pollatsek, \& Rayner, 1989; Henderson \& Ferreira, 1990; Inhoff, 1989a, 1989b, 1990; Inhoff, Pollatsek, Posner, \& Rayner, 1989; Inhoff \& Rayner, 1986; Lima, 1987; Lima \& Inhoff, 1985; Morris, Rayner, \& Pollatsek, 1990; Pollatsek, Rayner, \& Balota, 1986; Rayner, 1975; Rayner, Balota, \& Pollatsek, 1986; Rayner \& Morris, 1992; Rayner et al., 1982). Furthermore, readers are not necessarily constrained by the boundaries of the fixated word, in that at least some partial letter/word information may be extracted from the parafoveal region during reading. The advantage gained by the availability of useful information in the parafovea over the absence of useful information in the parafovea is called the parafoveal preview benefit (Rayner \& Pollatsek, 1989).

The parafoveal preview benefit is greatest when the entire word is available in the parafovea, suggesting that the preview benefit may have a lexical component (as opposed to being entirely orthographic). In a series of experiments, Inhoff and colleagues (Inhoff, 1989a, 1989b, 1990; Briihl \& Inhoff, 1995; Inhoff \& Tousman, 1990;
Lima \& Inhoff, 1985) found that all of the letters of a parafoveally available word contribute to its subsequent identification; however, this effect is not additive. Readers benefit from the availability of partial word information in the parafovea, but the preview benefit gained from wordinitial letters and word-final letters did not equal the benefit obtained from the availability of the entire word. Although ending letters contribute to parafoveal preprocessing, Briihl and Inhoff (1995; Inhoff, 1990) have argued that beginning letters appear to be of larger importance to the word identification process. They further suggested that word-initial letters provide linguistic constraints on the identification of noninitialletters. Thus, information available to the reader in the parafovea influences subsequent word processing by activating lexical representations. Finally, phonological (sound) codes influence subsequent word processing when previously available in the parafovea. Pollatsek, Lesch, Morris, and Rayner (1992) found a preview effect from a homophone of a subsequently fixated target word, in comparison with when the parafoveal word was orthographically similar to the target word.

However, some types of information do not seem to be obtained from the parafovea. For example, several studies (Altarriba, Kambe, Pollatsek, \& Rayner, 2001; Rayner et al., 1986; Rayner \& Morris, 1992) have failed to show any evidence to indicate that semantic information in the parafovea facilitates subsequent word processing. Rayner et al. (1986) asked participants to read sentences such as that shown in Figure 1. When the sentence was initially presented on the monitor, one of four preview conditions was initially displayed (see Figure 1). As the readers' eyes moved from the pretarget word (i.e., new) to the target region, the preview word (tune) was replaced with the target word (song). The only preview benefits found were those for the identical condition (song as the preview) and for the orthographically similar condition (sorp as the preview). There was no difference in parafoveal preview ben- 
efit between the semantically related (tune) and unrelated (door) conditions. Thus, the results reported in Rayner et al. (1986) failed to support the contention that semantic information is extracted from the parafovea.

Although most research has indicated that semantic information is not extracted from the parafovea, very few studies have examined whether morphological information is processed parafoveally. Morphemes are the smallest unit of meaning in the language, and they contain semantic, syntactic, and phonetic information. The semantic information contained within a morpheme is fairly consistent. Because morphemes contain some aspects of meaning, they are often considered to behave similarly to semantic information. However, there is a growing body of evidence indicating that morphemes are a unique level of linguistic representation, that they are treated differently than whole words (Rastle, Davis, Marslen-Wilson, \& Tyler, 2000), and that they play a role in word processing (e.g., Andrews, 1986; Coolen, van Jaarsveld, \& Schreuder, 1993; Feldman, 1994, 2000; Frost, Deutsch, Gilboa, Tannenbaum, \& Marslen-Wilson, 2000; Frost et al., 1997; Hyönä \& Pollatsek, 1998; Laudanna et al., 1989; Lima \& Pollatsek, 1983; Pollatsek et al., 2000; Prinzmetal, 1990; Sandra, 1990; Shillcock, 1990; Stolz \& Feldman, 1995; Taft, 1985; Taft \& Forster, 1976; van Jaarsveld \& Rattink, 1988; Zwitserlood, 1994).

This has led to a great deal of research focused on defining the role of morphology in word processing. This question has been of particular interest with respect to determining how morphologically complex words are represented in the mental lexicon. Several distinct theories have been developed to address how morphologically complex words are represented in the lexicon. The primary alternatives are that morphologically complex words are identified via (1) the whole word form (the full-listing hypothesis), (2) morphological constituents (e.g., the stem), and (3) both routes.

According to the full-listing hypothesis, words are represented and retrieved as their full forms (Butterworth, 1983). For example, all versions of the word vent (e.g., invent, advent, convent, venture, etc.) have their own lexical representation and are accessed as separate lexical entries. In contrast, according to a strong decomposition model, all words are stored and retrieved according to their morphological stems, so that advent and invent are accessed via the morphologicalunit vent. Thus, full word forms are derived from their morphemes in accordance with a set of morphological rules. Taft and Forster's (1976) prefixstripping hypothesis is another example of this type of model. In both cases, decomposition occurs prelexically. A third type of model posits that morphologically complex words are accessed via their whole word form and their individual morphemes (e.g., the interactive-activationmodel [Taft, 1991, 1994; Taft \& Zhu, 1994] and the augmented addressed model [Caramazza, Laudanna, \& Romani, 1988]). For the last type of model, both the morphological constituents and the whole word form are represented in the lexicon. Thus, word identification can occur via the individual morphemes or the whole word form.
Although the models above suggest that morphological information is available very early during word processing, none has addressed whether morphological information is available for preprocessing in the parafovea. In fact, only a few studies have addressed this issue to date. Inhoff (1989a) carried out a parafoveal preview experiment to determine whether morphological information was accessible in the parafovea. In his study, compound words, such as cowboy, were compared with pseudocompound words, such as carpet. The prediction was that if morphological information can be obtained parafoveally, compound words would benefit from a parafoveal preview of the initial letter string (e.g., cow), whereas pseudocompound words would not. There were four preview conditions in this experiment: (1) no preview, (2) the first three letters of the target word, (3) the first four letters of the target word, and (4) the entire target word. The three- and fourletter previews either corresponded to linguistically defined subword units or violated them. Inhoff (1989a) found no differences in parafoveal preview benefit with respect to the morphological status of the previewed letters: The preview benefits were similar when the preview letters formed morphological units and when they did not. Inhoff's (1989a) data provided evidence in support of a model of parafoveal word recognition driven by letter identification, but not by morphological identification.

Lima (1987) also investigated the effect of morphology on parafoveal processing. In a display change experiment, she compared prefixed words (e.g., revive) with pseudoprefixed words (e.g., rescue) placed within identical sentence contexts. Pseudoprefixed words have the same initial letter sequence as a prefixed word, but the initial letter sequence is not actually a separate morphological unit. Although Lima found a reading time difference between prefixed and pseudoprefixed words once they were fixated, she found no evidence to indicate that a parafoveal preview of the morphological unit ( prefix) facilitated subsequent word processing.

On the other hand, Deutsch and colleagues (Deutsch, Frost, Peleg, Pollatsek, \& Rayner, 2003; Deutsch, Frost, Pollatsek, \& Rayner, 2000) have reported a parafoveal morphological preview benefit for readers of Hebrew. Deutsch et al. (2000; Deutsch et al., 2003) also used the display change paradigm and found that if the root morpheme was available in the parafoveal preview, readers took less time reading the target word, in comparison with control conditions. Of course, Hebrew is a morphologically richer language than English, and the difference may be language specific. It is also interesting to note that the root morpheme is distributed throughout the word in $\mathrm{He}-$ brew and is not localized at the beginning or the end of the word. Given that Deutsch et al. (2000; Deutsch et al., 2003) found clear evidence for a preview benefit due to morphology, it is important to reexamine Lima's study in order to determine whether evidence for a morphological preview benefit can be obtained in English.

Although Lima (1987) found no difference between processing prefixed and pseudoprefixed words in the parafovea, it is possible that the different classes of pre- 
fixed words may behave differently. For example, research by Marslen-Wilson et al. (1994; see also Zwitserlood, 1994) has indicated that there is an important distinction to be made between prefixed words with a free stem versus a bound stem. Free-stem prefixed words consist of a prefix and a stem, where the stem is a recognizable word on its own (re-view). These are generally classified as orthographically transparent, a classification that typically results in a processing advantage over bound-stem prefixed words. In contrast, bound-stem prefixed words do not have orthographically transparent words as their stems (re-duce) and have generally been found to take longer to identify during masked priming tasks than free-stem prefixed words (Zwitserlood, 1994).

Presumably, if morphological information is available for processing in the parafovea, it is involved in the early stages of word processing during reading. This would result in a processing benefit for all types of prefixed, as opposed to pseudoprefixed, words. If morphological information is not available for processing in the parafovea, reading times should not differ for prefixed and pseudoprefixed words. This would suggest that the parafoveal preview benefit is driven primarily by low-level visual cues, orthographic and/or phonological components of the previews and target words. In previous research (McConkie \& Zola, 1979; Rayner, McConkie, \& Zola, 1980; see Rayner, 1998, for a summary), it has been concluded that the primary source of the preview benefit appears to be some type of an abstract code, because the letters of a word can change case without affecting reading behavior. In this research, it has been assumed that semantic (and morphological) information is not available for parafoveal preprocessing. Evidence for morphological preprocessing in the absence of evidence for semantic preprocessing would suggest that morphological structure, although including semantic information, is a unique level of linguistic representation. In addition, it would suggest that morphological information affects word processing at an earlier time point than does semantic information during lexical access. As a result, it is important to investigate morphological preprocessing separately from semantic preprocessing, since it is possible that morphological information may be extracted from the parafovea during reading even though semantic information is not. Thus, in the present research, the availability issue of morphological preprocessing was reexamined.

\section{EXPERIMENT 1}

As was noted above, Lima's (1987) research indicated that morphological information available in the parafovea does not facilitate subsequent word processing during reading in English. However, evidence reported by Deutsch et al. (2000; Deutsch et al., 2003) in Hebrew indicated that there was a preview benefit for morphological constituents. Although the difference in results may be language specific, morphological preprocessing in English warrants further investigation. In addition, it is possi- ble that free-stem and bound-stem prefixed words behave differently, so that free-stem prefixed words demonstrate the preview benefit, whereas bound-stem prefixed (and pseudoprefixed) words do not. The intent of the present research was thus twofold: (1) to reexamine whether morphological information can be obtained from the parafovea to facilitate processing and (2) to determine whether bound-stem and free-stem prefixed words are processed differently.

\section{Method}

Participants. Thirty-six members of the University of Massachusetts community participated in this experiment. All were native English speakers and were naive as to the purpose of the experiment. All the participants had normal or corrected-to-normal vision.

Apparatus. Eye movements were recorded by a Fourward Technologies Dual Purkinje eye tracker (Generation V). The eye tracker had a resolution of less than 10 min of arc. The participant's view of the screen was binocular, but only the right eye was monitored for eye location. The signal from the eye tracker was sampled every millisecond by a 486 computer. The single-line sentences were presented on a NEC MultiSync 4FG color monitor. The average vertical and horizontal positions of the eye were compared with the previous positions to determine whether the eye was fixated or moving. During the experiment, all the participants were seated $62 \mathrm{~cm}$ from the monitor, which displayed three characters subtending $1^{\circ}$ of visual angle. The letters were presented in light cyan (on a black background) by mixing green and blue input signals on the display monitor with a P-22 phosphor, which allowed blanking of the display to produce a drop to $10 \%$ of maximum brightness in $0.06 \mathrm{msec}$. The refresh rate of the monitor (averaging $160+\mathrm{Hz}$ ) and the 1-msec sampling rate of the eye-tracking system resulted in all the display changes occurring within $4 \mathrm{msec}$ (a saccade typically takes about $8-12 \mathrm{msec}$ ). The luminance of the screen was adjusted to a level of brightness that was most comfortable for the participant and then was held constant throughout the experiment. The experimental room was dark, except for a small indirect light, which enabled the experimenter to keep notes during the experiment.

Procedure. When a participant arrived for the experiment, he/she was given a general description of the experimental situation and procedure. The participants were told that they would be expected to read a series of sentences on a computer screen while their eye movements were being monitored. They were told to read the sentences for comprehension. Each participant read 12 practice trials, 108 experimental trials, and 54 filler trials. Approximately $30 \%$ of the sentences were followed by a question requiring a yes/no response made by clicking a button on a keypad. After each participant understood the procedure and signed an informed consent, a bite bar was prepared in order to minimize head movements.

Once the participant was seated in front of the monitor, an initial calibration procedure that took approximately 5 min was completed. Prior to each trial, the calibration was checked to ensure that accurate records were being obtained. If the calibration was good, the participant was instructed to fixate on the leftmost calibration box, and the experimenter initiated the trial. For each sentence, an invisible boundary was located immediately after the last letter of the word prior to the target word (see Figure 2). When the sentence was initially presented on the computer monitor, a preview word or letter string occupied the target word location. Once the participant's eyes moved across the boundary location during a saccade, the preview word or letter string was replaced by the target word (see Rayner, 1975, for a comprehensive description of this technique). Because the display change took place during a saccade (during which vision is suppressed), the participant was not aware of the display change. To ensure that this was true, the participant was asked 
* |

Mary wants to quickly rehsxc her credit card debt this year.

Mary wants to quickly reduce her credit card debt this year.

\author{
Preview Conditions, Experiment 1 \\ Identical $=$ reduce \\ Prefix only $=$ rehsxc \\ Stem only $=$ zvduce \\ Control $=z v h s x c$
}

Preview Conditions, Experiment 2

Identical $=$ reduce

Prefix only $=r e X X X X$

Stem only $=X X$ duce

Control $=X X X X X X$

Target word: reduce

The asterisk denotes the position of the eye, and the " "Idenotes the location of the boundary.

Figure 2. Example sentence for Experiments 1 and 2.

to report what he/she had noticed about the display changes at the end of the experiment. None of the participants reported having seen a display change during the experiment. When the participant finished reading the sentence, he/she pressed a button that blanked the monitor. Then either a yes/no question or the calibration screen reappeared on the monitor.

Materials. Target words consisted of prefixed words and pseudoprefixed words (words that shared the same initial letter sequence with a prefixed word but were not actually prefixed words). For the sake of simplicity, both the actual prefix and the pseudoprefix initial letter sequence will be referred to as the prefix, since the intent is to focus on the identical initial letter strings. Each target word was embedded in one of 108 experimental sentences, with 36 sentences assigned to each of three conditions: (1) pseudoprefixed (e.g., region), (2) bound-stem prefixed (e.g., reduce), and (3) free-stem prefixed (e.g., review) words. The mean Francis and Kučera (1982) word frequency rating for each of the word types was 32.28 (range: 0-213), 38.25 (range: 0-329), and 31.61 (range: 0-232), respectively.

Each target word was chosen and categorized in accordance with three criteria: (1) Webster's New World Dictionary (Neufeldt \& Guralnik, 1988), (2) Ayto's (1990) Dictionary of Word Origins, and (3) participant ratings (see below). No word was included in the experimental stimuli without being categorized as a particular word type according to all three criteria. An initial word list of over 250 words was prepared by two individuals with $98 \%$ interrater reliability (all words failing to be categorized in the same manner by the two individuals were dropped from the list before the rating study began). Words were categorized as free stem if the stem of the prefixed word could stand on its own as a word in the English language and as bound stem if they could not. The target words in each of the three conditions were matched according to overall word length, word frequency, and pronunciation of the prefix. Attempts were made to ensure that all three word lists contained an equivalent number of words of the same part of speech and number of word-initial letters (see the Appendix for target word information for the final word list). In the free-stem prefixed word condition, the stem word was orthographically transparent, in that no letters were altered or deleted; however, the free-stem prefixed words were not necessarily seman- tically transparent. The meaning of the word making up the stem of the prefixed word was always consistent with the overall meaning of the prefixed word containing the stem, but stem and root combinations sometimes resulted in a unique meaning. For example, whereas refill means to "fill again," return means to "go back," and not to "turn again." In the bound-stem prefix condition, common stems were used, all of which are familiar (and known to be word stems) to the local participant population (as determined by a rating study). Boundstem prefixed words were considered to be semantically opaque. Measures of semantic transparency did not apply for the pseudoprefix condition (since they are considered to be monomorphemic words), but every effort was made to ensure that all the words were common and familiar to the reader.

Three different participant ratings were conducted on various aspects of the words. Twenty-four University of Massachusetts undergraduates (who did not participate in either reading experiment) provided the participant ratings. The rating studies consisted of an initial word list of 268 free-stem prefixed, bound-stem prefixed, and pseudoprefixed words. Individuals were asked to perform two wordrating tasks. First, they were asked to categorize the three word types according to the morphological form (prefix) category definition (free stem, bound stem, or pseudoprefixed; category definitions were provided). ${ }^{1}$ The participants were then asked to rate how familiar each word was to them. Familiarity ratings were made on a scale of 1-10, with 10 indicating that the word was very familiar and 1 indicating that the word was unfamiliar to the participant. All the words included in the final word list of the experiment had a familiarity $^{2}$ rating of 8 or above (with an overall mean of 9.64). Because the results of the word classification task were somewhat surprising (only $88 \%$ of the free-stem prefixed words were correctly classified from the initial word list), another rating task was conducted to provide a potentially better measure of categorization. A separate group of 24 University of Massachusetts students were asked to look at a list containing the stem of the words from the original rating task. They were asked to simply indicate whether each letter string was a real word or not. The intent was to determine whether the stems of the free-stem prefixed words were recognizable. Any word failing to be classified as free-stem in the first rating task and all of the non- 
words rated as being potential words in the second rating task were dropped from the word list. Finally, a third group of six individuals (with linguistic training) subjectively rated the appropriateness of how the words were categorized (with category labels and definitions provided). All 108 words included in the experiments below were subjectively rated as being appropriately categorized by all 6 individuals (in addition to being correctly classified in all the previous rating tasks).

Each target word was placed in a neutral sentence context, preceded by at least two words. The word immediately prior to the target word was always at least 5 letters (with a maximum of 10 letters) long to increase the probability of fixating the target word. For each target word type, there were four preview conditions: (1) identical (e.g., review), in which the parafoveal preview was the same as the target word; (2) prefix only (e.g., rexwsz), in which the parafoveal preview consisted of the prefix from the target word followed by a random string of letters; (3) stem only (e.g., cmview), in which the parafoveal preview consisted of the stem of the word preceded by a random string of letters; and (4) control (e.g., cmxwsz), in which the parafoveal preview consisted of a random string of letters (see Figure 2). All the random letter sequences excluded vowels and were chosen so that the overall letter shape was consistent with the original target word letters (i.e., ascenders were replaced with ascenders, descenders with descenders, and nondescenders with nondescenders; Bouma, 1973). The random letter string was a no-preview control condition. The identical condition served as a baseline condition, since the information was the same in the parafovea as it was in the fovea. This no-change condition ${ }^{3}$ allowed for an examination of differences in word processing for the three target word conditions (without the interruption of a partial preview).

\section{Results}

Two eye movement measures were computed: (1) firstfixation duration (the duration of the first-fixation on target words during the sentence's initial first-pass reading, irrespective of the number of subsequent fixations on these words) and (2) gaze duration (the cumulated viewing time on a target word during its first-pass reading, excluding the time spent rereading the target after the reading of other words).

Data were excluded from the following analysis for any of the following reasons: (1) A track loss occurred; (2) the eyes triggered the boundary change but actually landed on the word prior to the target word (usually the last letter of this word); (3) the first fixation of the target word was less than $100 \mathrm{msec}$, or a first-pass fixation was greater than $800 \mathrm{msec}$; and (4) the first-pass fixation was the last fixation recorded for the sentence. After data were excluded from the analysis according to the criteria above, $88 \%$ of the data were left (and thus were included in the analyses reported below). The percentage of correct responses to the yes/no questions was $96 \%$, indicating that the participants had understood the sentences.

All eligible trials were subjected to 3 (target word type: free prefixed, bound prefixed, pseudoprefixed) $\times 4$ (preview type: identical, prefix only, stem only, control) analyses of variance (ANOVAs) with error variance computed within subjects $\left(F_{1}\right)$ and between items $\left(F_{2}\right)$. Planned contrasts were also performed to compare preview effect sizes.

Effect of word type. The results from the reading time measures are presented in Table 1. Neither first-fixation nor gaze duration times varied across the different types of prefixed and pseudoprefixed words (all $F_{\mathrm{S}}<1$ ). Furthermore, the interaction between word type and preview was not significant (all $F_{\mathrm{S}}<1$ ) for either reading time measure. The results of the present experiment are thus consistent with those of Lima (1987) and fail to provide evidence in support of morphological influences on early word processing during reading in English.

Effect of preview type. The effects for preview type (see Table 1) were quite consistent for both reading time measures (first fixation and gaze duration). Across both measures, there was a main effect of preview for first-fixation duration $\left[F_{1}(3,105)=11.94, M S_{\mathrm{e}}=835.09, p<.001\right.$; $\left.F_{2}(3,315)=12.14, M S_{\mathrm{e}}=864.56, p<.001\right]$ and gaze duration $\left[F_{1}(3,105)=10.47, M S_{\mathrm{e}}=1,087.11, p<.001\right.$; $\left.F_{2}(3,315)=8.37, M S_{\mathrm{e}}=1,364.31, p<.001\right]$. The difference between the prefix-only and the stem-only conditions was not significant for first-fixation duration or gaze duration $\left(F_{\mathrm{s}}<1\right)$. As a result, all planned pairwise comparisons were made against the combined partial preview conditions. When the entire target word was available in the parafovea (the identical condition), subsequent gaze durations on the target word were significantly shorter than those in the control condition [first-fixation duration, $F_{1}(1,35)=25.60, M S_{\mathrm{e}}=6,512.68, p<.001$, and $F_{2}(1,105)=30.98, M S_{\mathrm{e}}=1,892.26, p<.001$; gaze duration, $F_{1}(1,35)=22.45, M S_{\mathrm{e}}=8,881.51, p<.001$, and $\left.F_{2}(1,105)=22.51, M S_{\mathrm{e}}=2,884.17, p<.001\right]$ and the partial preview conditions [first-fixation duration, $F_{1}(1,35)=24.02, M S_{\mathrm{e}}=12,058.28, p<.001$, and $F_{2}(1,105)=23.46, M S_{\mathrm{e}}=4,581.67, p<.001 ;$ gaze duration, $F_{1}(1,35)=16.75, M S_{\mathrm{e}}=17,063.07, p<.001$, and $\left.F_{2}(1,105)=16.20, M S_{\mathrm{e}}=6,777.83, p<.001\right]$. The target word was read more quickly in the partial preview conditions than in the control condition [first-fixation duration, $F_{1}(1,35)=6.58, M S_{\mathrm{e}}=11,784.48, p<.05$, and $F_{2}(1,105)=3.75, M S_{\mathrm{e}}=6,522.52, p<.06$; gaze duration, $F_{1}(1,35)=7.21, M S_{\mathrm{e}}=17,810.89, p<.05$, and $\left.F_{2}(1,105)=3.68, M S_{\mathrm{e}}=8,628.69, p<.06\right]$. Thus, although the preview benefit was strongest when the entire target word was available in the parafovea, having partial word information in the parafovea appeared to benefit subsequent word processing regardless of whether the information was word initial or word final.

The degree of facilitation found when only the stem of the target word was available in the parafovea for preprocessing was somewhat surprising. Some preview benefit was expected for the end of the word, but not a similar degree of facilitation, as was found when the initial part of the target word was available in the parafovea. As a result, a post hoc analysis was run to determine whether the location of the eye prior to fixating the word modulated the strength of the preview benefit found for the partial preview conditions. That is, would the degree of facilitation for the end of the word decrease if the eye was farther away from the target word on the prior fixation? To address this question, the data were divided into two groups. The near group included all trials in which the readers' eyes were within 1-4 character spaces of the target word before making a forward saccade onto the target word. 
Table 1

Mean First-Fixation Duration (FFD, in Milliseconds) and Gaze Duration (GD, in Milliseconds) on the Target Word in Experiment 1

\begin{tabular}{|c|c|c|c|c|c|c|}
\hline \multirow[b]{2}{*}{ Condition } & \multicolumn{2}{|c|}{ Pseudoprefix } & \multicolumn{2}{|c|}{ Bound-Stem Prefix } & \multicolumn{2}{|c|}{ Free-Stem Prefix } \\
\hline & FFD & GD & FFD & GD & FFD & GD \\
\hline Identical & 255 & 286 & 264 & 303 & 268 & 289 \\
\hline Prefix only & 280 & 307 & 279 & 308 & 279 & 312 \\
\hline Stem only & 274 & 302 & 279 & 310 & 274 & 308 \\
\hline Control & 283 & 313 & 283 & 320 & 289 & 320 \\
\hline
\end{tabular}

The far group consisted of all trials in which the eyes were within 5-10 characters of the target word. The near group contained $48 \%$ of the overall data, and the far group contained $50 \%$ of the overall data. Trials in which the eyes were farther than 10 character spaces or the reader regressed to an earlier portion of the text before entering the target word (which comprised $2 \%$ of the data) were excluded from this analysis. This analysis yielded only a main effect of preview type $\left[F_{1}(3,168)=7.35, M S_{\mathrm{e}}=\right.$ $3,048.13, p<.001 ; F_{2}(3,588)=11.19, M S_{\mathrm{e}}=3,634.48$, $p<.001$ ], which was entirely consistent with the previously reported analysis. There was no main effect of either word type or distance $\left(F_{\mathrm{S}}<1\right)$, and neither the interaction between preview and word type nor the interaction between preview and distance was significant (all $F \mathrm{~s}<1$ ).

\section{Discussion}

There were several interesting results of the above analyses. First, there was no evidence of morphological influences on early measures of word processing. No evidence was found to suggest that morphological constituents facilitate early word processing in parafoveal vision. Second, the parafoveal preview benefit was consistently greatest for the identical condition. Third, both partial preview conditions resulted in facilitation during word processing. Finally, there was no interaction between word type and preview type for any of the reading time measures.

The readers were benefited the most by having the entire word available in the parafovea. This is consistent with Inhoff and colleague's (Briihl \& Inhoff, 1995; Inhoff, 1989a, 1989b, 1990; Inhoff \& Tousman, 1990; Lima \& Inhoff, 1985) findings on the parafoveal preview benefit. The parafoveal preview benefit for the identical condition was greater than that for the word-initial preview condition (with similarly shaped word-final letters), suggesting one of two alternatives: that the preview benefit has a lexical component or that it is the result of a cumulative orthographic effect driven by exact letter matches in the parafovea and fovea (as opposed to just similarly shaped letters). The preview benefit was greatest for the identical condition regardless of word type and distance of the eyes to the target word. Interestingly, a preview benefit was evident for both partial preview conditions.

It is also important to note that prefixed and pseudoprefixed words were benefited by having the prefix and stem letters in the parafovea. Furthermore, there was no interaction between word type and preview type for either of the reading time measures. The failure to find an inter- action between word type and preview type is a bit puzzling. Morphological constituents (such as the stem of the prefixed word) have been found to benefit subsequent word processing when words are presented in isolation (e.g., Andrews, 1986; Coolen et al., 1993; Feldman, 1994, 2000; Laudanna et al., 1989; Prinzmetal, 1990; Sandra, 1990; Shillcock, 1990; Stolz \& Feldman, 1995; Taft, 1985; Taft \& Forster, 1976; Van Jaarsveld \& Rattink, 1988; Zwitserlood, 1994). In the present experiment, the freestem words were expected to demonstrate a similar processing advantage when the stem was made available for parafoveal preview. Free-stem words were expected to have an advantage over both bound-stem and pseudoprefixed words because the free-stem words were all orthographically transparent and the meaning of the stem was consistent with the overall word meaning. This hypothesis is plausible, considering the reliable preview benefit found for the stem-only condition across all word types.

Another possible explanation for the lack of an interaction between word type and preview type is that the consonant letter strings used in the present experiment (presented parafoveally) interfered with subsequent word processing. For example, reduce had the consonant letter string -hsxc in place of the stem -duce, and return had the consonant letter string $-f c z x$ in place of -turn. In both cases, the resulting word-initial trigram (visible in the parafovea) was common within the English language (e.g., rehearse and refund). Previous research has verified the availability of both phonological and orthographic information from word-initial letters in the parafovea (see Rayner, 1998, for a review). Thus, the word-initial letter string in the prefix-only condition may have originally been interpreted as reh- or ref-instead of re-, thus impeding word processing when the target word was subsequently fixated and, thereby, preventing any resulting benefit for prefixed words over pseudoprefixed words. The interference caused by the consonant letter string in the stem-only preview condition could have disrupted processing in the same manner. As a result, a second experiment was conducted to determine whether the consonant letter string in the parafovea was interfering with subsequent word processing, thus masking any benefit resulting from a parafoveal preview of morphological constituents.

\section{EXPERIMENT 2}

In the previous experiment, the consonant letter string used to replace the target word letters in the partial pre- 
view conditions may have been interpreted as part of the preview word. The present experiment was performed to examine whether the consonant letter string presented in the parafovea disrupted subsequent word processing. In a large number of the stimuli, the initial trigram formed by the combination of the prefix and the consonant letter string was (1) common and (2) an initial letter sequence for a viable word in the English language. Removing the similarly shaped letters from the parafovea and restricting the parafoveal preview to the exact prefix or stem of the target word might provide a better test of the influence of morphology in parafoveal preprocessing. In order to restrict the parafoveal preview to the appropriate letters in the partial preview conditions, capital Xs were used. Capital Xs are visually distinct (XXview) and do not combine with any of the target word letters to form a word (reXXXX), thus making it possible to ascertain whether prefixed words are benefited by the availability of morphological information in the parafovea.

\section{Method}

Participants. Twenty-four members of the University of Massachusetts community participated in this experiment. All were native English speakers and were naive as to the purpose of the experiment. All the participants had normal or corrected-to-normal vision. None had participated in the prior experiment.

Apparatus. The apparatus was the same as that in Experiment 1.

Procedure. The procedure for this experiment was the same as that in Experiment 1.

Materials. The target words and sentence contexts were identical to those in Experiment 1. The information presented in the parafovea was modified to prevent confusion. Instead of replacing the target word letters with visually similar consonant strings, capital Xs were used. Thus, the four preview conditions were (1) identical (e.g., review), in which the parafoveal preview was the same as the target word; (2) prefix only (e.g., reXXXX), in which the parafoveal preview consisted of the prefix from the target word, followed by a series of capital Xs; (3) stem only (e.g., XXview), in which the parafoveal preview consisted of the stem of the word, preceded by capital $\mathrm{Xs}$; and (4) control (e.g., XXXXXX), in which the parafoveal preview consisted entirely of capital Xs (see Figure 2).

\section{Results}

The following measures were again computed: (1) firstfixation duration and (2) gaze duration. Data were excluded from the following analysis according to the same criteria as those in Experiment 1. Once the criteria for data exclusion were applied for all the participants, the remaining percentage of usable data was $89 \%$. The partici- pants' responses averaged $97 \%$ correct on the yes/no questions, again indicating that they had understood the sentences. The readers reported some awareness of the Xs in the parafovea during this experiment; however, the number of trials in which the Xs were reported significantly underestimated the total number of trials in which they had actually occurred.

All the eligible trials were subjected to 3 (target word type: free prefixed, bound prefixed, or pseudoprefixed) $\times 4$ (preview type: identical, prefix only, stem only, or control) ANOVAs with error variance computed within subjects $\left(F_{1}\right)$ and between items $\left(F_{2}\right)$. As in the previous experiment, planned contrasts were performed to compare preview effect sizes.

Effect of word type. Neither first-fixation nor gaze duration measures varied across the different types of prefixed and pseudoprefixed words (all $F_{\mathrm{s}}<1$ ). There was no interaction between word type and preview type (all $\left.F_{\mathrm{S}}<1\right)$ for either of the reading time measures. These results again fail to support the hypothesis that morphological preprocessing occurs in the parafovea. Furthermore, these results suggest that the characteristics of the partial preview condition in the prior experiment did not mask processing differences among the three word types (see Table 2).

Effect of preview type. As in Experiment 1, the effect of preview type was quite consistent for both reading time measures (first fixation and gaze duration). There was again a main effect of preview for first-fixation duration $\left[F_{1}(3,69)=17.43, M S_{\mathrm{e}}=1,517.09, p<.001 ; F_{2}(3,315)=\right.$ $\left.25.64, M S_{\mathrm{e}}=1,612.58, p<.001\right]$ and gaze duration $\left[F_{1}(3,69)=12.54, M S_{\mathrm{e}}=2,714.37, p<.001 ; F_{2}(3,315)=\right.$ $\left.17.09, M S_{\mathrm{e}}=2,847.89, p<.001\right]$. Reading times were shortest in the identical condition and longest in the control condition. The difference between the prefix-only and the stem-only conditions was not significant $\left(F_{\mathrm{S}}<1\right)$. As a result, the planned pairwise comparisons were made against the combined partial preview conditions. Reading times for the identical preview condition were significantly shorter than those in both the control condition [first-fixation duration, $F_{1}(1,23)=27.48, M S_{\mathrm{e}}=$ $15,362.25, p<.001$, and $F_{2}(1,105)=64.99, M S_{\mathrm{e}}=$ $3,370.45, p=.001$; gaze duration, $F_{1}(1,23)=29.06$, $M S_{\mathrm{e}}=20,735.65, p<.001$, and $F_{2}(1,105)=51.91$, $\left.M S_{\mathrm{e}}=5,482.53, p<.001\right]$ and the partial preview conditions [first-fixation duration, $F_{1}(1,23)=26.45, M S_{\mathrm{e}}=$

Table 2

Mean Gaze Duration (in Milliseconds) for the Near and Far Groups on the Target Word in Experiment 1

\begin{tabular}{|c|c|c|c|c|c|c|}
\hline \multirow[b]{2}{*}{ Condition } & \multicolumn{2}{|c|}{ Pseudoprefix } & \multicolumn{2}{|c|}{ Bound-Stem Prefix } & \multicolumn{2}{|c|}{ Free-Stem Prefix } \\
\hline & Near & Far & Near & Far & Near & Far \\
\hline Identical & 261 & 291 & 294 & 313 & 285 & 298 \\
\hline Prefix only & 297 & 298 & 300 & 316 & 318 & 298 \\
\hline Stem only & 294 & 308 & 314 & 325 & 304 & 300 \\
\hline Control & 309 & 320 & 307 & 334 & 322 & 315 \\
\hline
\end{tabular}


$31,030.43, p<.001$, and $F_{2}(1,105)=55.01, M S_{\mathrm{e}}=$ $8,068.94, p<.001$; gaze duration, $F_{1}(1,23)=15.08$, $M S_{\mathrm{e}}=55,216.74, p<.01$, and $F_{2}(1,105)=28.99$, $\left.M S_{\mathrm{e}}=14,360.42, p<.001\right]$. The target word was read more quickly after the partial preview conditions than after the control condition for first-fixation duration $\left[F_{1}(1,23)=6.72, M S_{\mathrm{e}}=23,051.88, p<.05 ; F_{2}(1,105)=\right.$ $\left.5.65, M S_{\mathrm{e}}=12,879.71, p<.05\right]$ and gaze duration $\left[F_{1}(1,23)=6.24, M S_{\mathrm{e}}=65,635.03, p<.05 ; F_{2}(1,105)=\right.$ $\left.9.88, M S_{\mathrm{e}}=17,996.58, p<.05\right]$. Again, the participants demonstrated the most preview benefit when the entire word was in the parafovea. However, gaze durations were facilitated for both the prefix-only and the stem-only preview conditions, as compared with the control condition. Thus, it did not seem to matter which part of the word was available for preview; preview benefit accrued from the beginning and the end of the word.

As in Experiment 1, the data from the present experiment were divided into two groups: near (between 1 and 4 characters) and far (between 5 and 10 characters). The near group contained $40 \%$ and the far group contained $39 \%$ of the overall data. Trials in which the eyes were farther than 10 character spaces or the reader regressed to an earlier portion of the text before entering the target word (which comprised an additional $21 \%$ of the data) were excluded from this analysis. As in Experiment 1, the only statistically significant effect was the main effect of preview type $\left[F_{1}(3,126)=14.21, M S_{\mathrm{e}}=4,899.66, p<.001\right.$; $\left.F_{2}(3,480)=11.42, M S_{\mathrm{e}}=7,053.29, p<.001\right]$. There was no main effect of either word type or distance $\left(F_{\mathrm{S}}<1\right)$, and neither the interaction between word type and preview nor that between word type and distance was significant (all $F_{\mathrm{S}}<1$ ).

As was noted above, in both Experiment 1 and Experiment 2 , there was no effect of word type. When the experiments were designed, it was assumed that parafoveal processing could benefit by having a morphological constituent in the parafovea. In particular, it seemed quite possible that the stem of free-stem prefixed words might facilitate subsequent word processing, even if no such facilitation was found for bound-stem prefixed words. However, not all of the free-stem prefixed words were semantically transparent. As a result, a post hoc items analysis was conducted to determine whether a preview benefit would be apparent for the semantically transparent free-stem prefixed words, as opposed to the nontransparent free-stem prefixed words. There was no evidence that parafoveal preview of a semantically transparent freestem prefixed word facilitated subsequent processing for either experiment. There was no effect of semantic transparency and no interaction between semantic transparency and preview type for first-fixation duration or gaze duration (all $F_{\mathrm{S}}<1$ ). However, as would be expected from the analyses already reported, there was an effect of preview in both experiments [Experiment $1, F_{2}(3,102)=4.76$, $M S_{\mathrm{e}}=1,212.88, p<.01$; Experiment $2, F_{2}(3,102)=$ $\left.11.20, M S_{\mathrm{e}}=1,615.55, p<.001\right]$, with reading times being shortest for the identical condition and longest for the control condition.
Finally, for both experiments, analyses were undertaken to determine whether there were any effects on saccade length into the target word and initial landing position of the eyes in the target word as a function of word type or preview. Across the two experiments, there were some small differences (on the order of 0.1-0.2 letter spaces), but they were not consistent and seemed to be due largely to random initial launch site differences.

\section{Discussion}

In Experiment 2, as in Experiment 1, there was no effect of word type for first-fixation duration or gaze duration on the target word. This failure to find word type effects in first-fixation duration and gaze duration suggests that morphological preprocessing is not apparent during reading. This finding is consistent with Lima's (1987) study, in which she found no effect of a parafoveal preview of the morphological constituents on subsequent word processing.

In Experiment 1, the potentially confusing letters used as the consonant letter strings might have interfered with the parafoveal preview benefit for prefixed words. In Experiment 2 , visually distinct capital $X$ letter strings were used to mask portions of the target word in the parafovea. This manipulation was intended to avoid providing misleading information in the parafovea about word components, allowing for a better test of whether morphological information is (1) available and (2) utilized in the parafovea during sentence processing. The results of the two parafoveal preview experiments were consistent. In both cases, there were no reading time differences for the various word types for first-fixation duration or gaze duration. Furthermore, there was no interaction between word type and preview type, suggesting that morphological information had no effect on parafoveal preprocessing during reading. The parafoveal preview benefit found was not influenced by morphological constituents. All three word types were benefited equally by having information available for preprocessing in the parafovea. Furthermore, post hoc analyses on semantic transparency again failed to show any evidence that morphological preprocessing occurs for semantically transparent free-stem prefixed words.

The identical preview condition resulted in the most parafoveal preview benefit across all word types. This suggests that having the exact letter string in the parafovea benefits subsequent word processing the most. Furthermore, reading times were facilitated on the target word for the partial preview conditions, so that the readers were benefited by having letters from both the beginning and the end of the word available in the parafovea. Thus, it appears that a parafoveal preview benefit can be obtained when relevant information is available in both the wordfinal and the word-initial positions. Again, the distance of the eyes prior to fixating the target word did not significantly modulate the parafoveal preview effect found in the present experiment, suggesting that the readers were benefited by having word-final letters available in the parafovea as much as 10 character spaces away from the target 
Table 3

Mean First-Fixation Duration (FFD, in Milliseconds) and Gaze Duration (GD, in Milliseconds) on the Target Word in Experiment 2

\begin{tabular}{|c|c|c|c|c|c|c|}
\hline \multirow[b]{2}{*}{ Condition } & \multicolumn{2}{|c|}{ Pseudoprefix } & \multicolumn{2}{|c|}{ Bound-Stem Prefix } & \multicolumn{2}{|c|}{ Free-Stem Prefix } \\
\hline & FFD & GD & FFD & GD & FFD & GD \\
\hline Identical & 264 & 308 & 266 & 299 & 268 & 296 \\
\hline Prefix only & 297 & 330 & 302 & 334 & 306 & 330 \\
\hline Stem only & 290 & 334 & 298 & 332 & 287 & 334 \\
\hline Control & 310 & 354 & 307 & 349 & 313 & 358 \\
\hline
\end{tabular}

word. The readers were clearly able to utilize distant information, particularly when the entire word was available for preprocessing.

\section{GENERAL DISCUSSION}

Previous research has established that processing may begin on a word before it has been fixated-when the word is in the parafovea. The information that is acquired when readers preview a word within the parafovea benefits subsequent word processing. This parafoveal preview benefit has been established when orthographic and/or phonological information is available in the parafovea for preprocessing. This suggests that orthographic and phonological information is involved in the initial stages of word processing. Semantic information, however, does not appear to be available for processing in the parafovea. This suggests that semantic information may constitute a later stage of the word identification process. Although morphological constituents contain semantic as well as phonologic/orthographic information, as was noted in the introduction, there is a growing body of literature to suggest that morphology is a unique level of linguistic representation. If morphological information does represent a unique level of linguistic representation, it is possible that morphological constituents influence word processing via parafoveal preview. The present experiments, like those in Lima (1987), failed to show any evidence of preview benefit due to morphological processing. Unlike Lima, however, there were no differences in reading times for the various word types once the target words had been fixated.

Although it is difficult to isolate the various stages of reading and word processing, the initial stages of word processing can be influenced by manipulating the availability of information in the parafovea. By manipulating the availability of morphological information in the parafovea, it was possible in the present experiments to investigate whether a parafoveal preview of a morphological constituent benefits subsequent word processing during reading. The type and availability of morphologicalinformation was manipulated in two parafoveal display change experiments. The availability of morphological information was manipulated by blocking what information was accessible in the parafovea for preprocessing across three different word types (free-stem prefixed words, boundstem prefixed words, and pseudoprefixed words). The information made available in the parafovea consisted of
(1) the entire word (the identical condition), (2) the wordinitial morpheme (the prefix-only condition), (3) the word-final morpheme (the stem-only condition), and (4) nonsense information (the control condition).

If morphological information influences initial processing, shorter reading times should occur for prefixed words than for pseudoprefixed words after a parafoveal preview of a morphological constituent. However, in both experiments, parafoveal preview of a morphological constituent failed to facilitate subsequent word processing. There was no evidence that morphological information was being accessed in the parafovea. The preview benefit was the same for all word types, and there was no interaction between preview and word type. This suggests that morphological information is not available for preprocessing in the parafovea.

Other research has suggested that morphological information is available in the parafovea to facilitate subsequent word processing. In fact, recent research by Deutsch, Frost, Pollatsek, and Rayner (2000; Deutsch et al., 2003) demonstrated a parafoveal preview benefit for Hebrew words that shared the derivational unit of the stem during sentence processing. Deutsch et al. (2000; Deutsch et al., 2003) conducted parafoveal display change experiments in which they found a significant morphological preview effect for words that did not share initial letters, suggesting that morphological units mediate word identification in Hebrew. It is possible, however, that these effects are specific to highly inflected languages (e.g., Hebrew, Finnish, or Turkish), where morphological information is more informative. Languages such as English make relatively limited use of morphology (see Plaut \& Gonnerman, 2000 , for a discussion); thus, reliance on morphological constituents during word processing may not be maximally efficient. Although there are occasions in which decomposition may be the fastest route to word identification, this will not always be the case in English. In contrast, a process by which morphologically complex words are decomposed prelexically may represent the most efficient means by which word identification could occur in highly inflected languages such as Hebrew.

Although, in the present investigation, there was no evidence to indicate that morphological constituents facilitate subsequent word processing in the parafovea during reading, several interesting preview effects were found. Experiments 1 and 2 demonstrated that when partial word information was available in the parafovea, reading times 
Table 4

Mean Gaze Duration (in Milliseconds) for the Near and Far Groups on the Target Word in Experiment 2

\begin{tabular}{|c|c|c|c|c|c|c|}
\hline \multirow[b]{2}{*}{ Condition } & \multicolumn{2}{|c|}{ Pseudoprefix } & \multicolumn{2}{|c|}{ Bound-Stem Prefix } & \multicolumn{2}{|c|}{ Free-Stem Prefix } \\
\hline & Near & Far & Near & Far & Near & Far \\
\hline Identical & 279 & 328 & 276 & 322 & 285 & 302 \\
\hline Prefix only & 330 & 345 & 324 & 349 & 331 & 313 \\
\hline Stem only & 323 & 341 & 338 & 315 & 338 & 315 \\
\hline Control & 361 & 342 & 344 & 355 & 358 & 368 \\
\hline
\end{tabular}

were facilitated. There was clear evidence that facilitation resulted from a parafoveal preview of the prefix (in the prefix-only condition) as well as of the stem (in the stemonly condition), suggesting that readers are benefited by parafoveal information obtained from both the beginning and the end of a word.

Although most research on the parafoveal preview benefit has shown a greater preview benefit for word-initial than for word-final letters (Balota et al., 1985; Blanchard et al., 1989; Henderson \& Ferreira, 1990; Inhoff, 1989a, 1989b, 1990; Inhoff et al., 1989; Inhoff \& Rayner, 1986; Lima, 1987; Lima \& Inhoff, 1985; Morris et al., 1990; Pollatsek et al., 1986; Rayner, 1975; Rayner et al., 1986; Rayner \& Morris, 1992; Rayner et al., 1982), the results of the present experiments are not entirely inconsistent with the previous research. The number of letters available in the parafovea for the partial preview conditions differed in both Experiments 1 and 2 . The stem-only condition (word final) had a higher average number of letters (range: $2-5$ letters) than did the prefix-only (word initial) preview condition (range: 1-3 letters). It is possible that this difference resulted in a tradeoff in preview benefit: Having more letters available for preprocessing in the word-final than in the word-initial position resulted in a preview benefit for the two conditions.

Inhoff (1990) compared preview benefits for the beginning and the ending letters in a word in which the number of word-initial and the number of word-final letters were equivalent (each consisting of three characters). Although he found evidence of a parafoveal preview benefit from word-final letters (Briihl \& Inhoff, 1995; Inhoff, 1990), Inhoff also consistently observed a greater parafoveal preview benefit for word-initial than for word-final letters even when reading was from right to left. It is entirely possible that by adjusting the amount and location of available information in the parafovea, the preview benefit can be modulated. The present research demonstrated that a parafoveal preview of word-final letters can benefit subsequent word processing. Furthermore, the preview benefit found for word-final letters was similar to that found for wordinitial letters. This finding has important implications for determining the characteristics of the parafoveal preview benefit and should be explored further in subsequent research.

Although a parafoveal preview benefit was found for word-initial and word-final letters, the preview benefit was always greatest when the entire word was available for preview (the identical condition). The increased facilitation for the identical as opposed to the partial preview conditions may have been the result of a cumulative orthographic effect. Previous research (Inhoff, 1989a, 1989b; Rayner et al., 1982) has indicated that orthographic information is readily available and utilized in the parafovea. By increasing the amount of relevant orthographic information, a subsequent increase in the parafoveal preview benefit may occur. An alternative explanation, however, has been proposed by Inhoff (1989b; see also Briihl \& Inhoff, 1995; Inhoff, 1989a, 1990; Inhoff \& Tousman, 1990; Lima \& Inhoff, 1985), who suggested that the additional facilitation found for the identical condition occurs because word-initial letters act in concert with word-final letters, mutually reinforcing each other, resulting in the cumulative preview benefit observed in the identical condition. Since the combined preview benefit found for the beginning and the ending letter conditions did not equal the preview benefit found in the identical condition, Inhoff (1989b) suggested that the parafoveal preview benefit obtained in the identical condition had a lexical component. The parafoveal preview benefit was greatest when the entire word was available in the parafovea, suggesting that all of the letters of a to-be-identified word contribute to its identification. This finding is consistent with both of the above hypotheses. Thus, further investigation (outside the scope of the present research) is required before a distinction can be made between these two hypotheses.

\section{REFERENCES}

Altarriba, J., Kambe, G., Pollatse K, A., \& Rayner, K. (2001). Semantic codes are not used in integrating information across eye fixations in reading: Evidence from fluent Spanish-English bilinguals. Perception \& Psychophysics, 63, 875-890.

ANDREWS, S. (1986). Morphological influences on lexical access: Lexical or nonlexical effects? Journal of Memory \& Language, 25, 726740 .

AYto, J. (1990). Dictionary of word origins. New York: Arcade.

Balota, D. A., Pollatse K, A., \& Rayner, K. (1985). The interaction of contextual constraints and parafoveal visual information in reading. Cognitive Psychology, 17, 364-390.

BERTRAM, R., Hy ÖNÄ, J., \& LAINE, M. (2000). The role of context in morphological processing: Evidence from Finnish. Language \& Cognitive Processes, 15, 329-366.

Binder, K. S., Pollatse K, A., \& Rayner, K. (1999). Extraction of information to the left of the fixated word in reading. Journal of Experimental Psychology: Human Perception \& Performance, 25, 1142-1158.

Blanchard, H. E., Pollatse K, A., \& Rayner, K. (1989). The acquisition of parafoveal word information in reading. Perception \& Psychophysics, 46, 85-94.

BoumA, H. (1973). Visual interference in the parafoveal recognition of initial and final letters of words. Vision Research, 13, 767-782. 
BRIIHL, D., \& INHOFF, A. W. (1995). Integrating information across fixations during reading: The use of orthographic bodies and exterior letters. Journal of Experimental Psychology: Learning, Memory, \& Cognition, 21, 55-67.

Butterworth, B. (1983). Lexical representation. In B. Butterworth (Ed.), Language production (Vol. 2, pp. 257-294). San Diego: Academic Press.

Caramazza, A., Laudanna, A., \& Romani, C. (1988). Lexical access and inflectional morphology. Cognition, 28, 297-332.

Coolen, R., van JaArsveld, H. J., \& Schreuder, R. (1993). Processing novel compounds: Evidence for interactive meaning activation of ambiguous nouns. Memory \& Cognition, 21, 235-246.

Deustch, A., Frost, R., \& Forster, K. (1998). Verbs and nouns are organized and accessed differently in the mental lexicon: Evidence from Hebrew. Journal of Experimental Psychology: Learning, Memory, \& Cognition, 24, 1238-1255.

Deutsch, A., Frost, R., Peleg, S., Pollatse K, A., \& Rayner, K. (2003). Early morphological effects in reading: Evidence from parafoveal preview benefit in Hebrew. Psychonomic Bulletin \& Review, 10, 415-422.

Deutsch, A., Frost, R., PollatseK,A., \& RAyner, K. (2000). Early morphological effects in word recognition in Hebrew: Evidence from parafoveal preview benefit. Language \& Cognitive Processes, 15, 487-506.

Drews, E., \& ZWISTERLOOD, P. (1995). Morphological and orthographic similarity in visual word recognition. Journal of Experimental Psychology: Human Perception \& Performance, 21, 1098-1116.

FELDMAN, L. B. (1994). Beyond orthography and phonology:Difference between inflections and derivations. Journal of Memory \& Language, 33, 442-470.

FELDMAN, L. B. (2000). Are morphological effects distinguishable from the effects of shared meaning and shared form? Journal of Experimental Psychology: Learning, Memory, \& Cognition, 26, 1431-1444.

FrANCIS, N., \& KUČERA, H. (1982). Frequency analysis of English usage: Lexicon and grammar. Boston: Houghton Mifflin.

Frost, R., Deutsch, A., Gilboa, O., TANnenbaum, M., \& MarslenWilson, W. (2000). Morphological priming: Disassociation of phonological, semantic, and morphological factors. Memory \& Cognition, 28, 1277-1288.

Frost, R., Forster, K. I., \& Deutsch, A. (1997). What can we learn from the morphology of Hebrew? A masked priming investigation of morphological representation. Journal of Experimental Psychology: Learning, Memory, \& Cognition, 23, 829-856.

GIRAUDO, H., \& GRAINGER, J. (2000). Effects of prime word frequency and cumulative root frequency in masked morphological priming. Language \& Cognitive Processes, 15, 421-444.

Grainger, J., Cole, P., \& Segui, J. (1991). Masked morphological priming in visual word recognition. Journal of Memory \& Language, 30, 370-384.

Henderson, J. M., \& Ferreira, F. (1990). Effects of foveal processing difficulty on the perceptual span in reading: Implications for attention and eye movement control. Journal of Experimental Psychology: Learning, Memory, \& Cognition, 16, 417-429.

HY ÖNÄ, J., \& POLLATSEK, A. (1998). Reading Finnish compound words: Eye fixations are affected by component morphemes. Journal of Experimental Psychology: Human Perception \& Performance, 24, 1612-1627.

INHOFF, A. W. (1989a). Lexical access during eye fixations in reading: Are word access codes used to integrate lexical information across interword fixations? Journal of Memory \& Language, 28, 444-461.

INHOFF, A. W. (1989b). Parafoveal processing of words and saccade computation during eye fixations in reading. Journal of Experimental Psychology: Human Perception \& Performance, 15, 544-555.

INHOFF, A. W. (1990). Integrating information across eye fixations in reading: The role of letter and word units. Acta Psychologica, 73, 281-297.

INHOFF, A. W., BRIIHL, D., \& SCHWARTZ, J. (1996). Compound word effects differ in reading, on-line naming, and delayed naming tasks. Memory \& Cognition, 24, 466-476.

Inhoff, A. W., Pollatsek, A., Posner, M. I., \& Rayner, K. (1989). Covert attention and eye movements during reading. Quarterly Journal of Experimental Psychology, 41A, 63-89.

INHOFF, A. W., \& RAYNER, K. (1986). Parafoveal word processing dur- ing eye fixations in reading: Effects of word frequency. Perception \& Psychophysics, 40, 431-439.

INHOFF, A. W., STARR, M., LIU, W., \& WANG, J. (1998). Eye-movementcontingent display changes are not compromised by flicker and phosphor persistence. Psychonomic Bulletin \& Review, 5, 101-106.

INHOFF, A. W., \& Tousman, S. (1990). Lexical priming from partialword previews. Journal of Experimental Psychology: Learning, Memory, \& Cognition, 16, 825-836.

Laudanna, A., Badecker, W., \& Caramazza, A. (1989). Priming homographic stems. Journal of Memory \& Language, 28, 531-546.

LIMA, S. D. (1987). Morphological analysis in sentence reading. Journal of Memory \& Language, 26, 84-99.

LIMA, S. D., \& INHOFF, A. W. (1985). Lexical access during eye fixations in reading: Effects of word-initial letter sequences. Journal of Experimental Psychology: Human Perception \& Performance, 11, 272-285.

Lima, S. D., \& PollatseK, A. (1983). Lexical access via an orthographic code? The basic orthographic syllabic structure (BOSS) reconsidered. Journal of Verbal Learning \& Verbal Behavior, 22, 310-322.

Marslen-Wilson, W., Tyler, L. K., Waksler, R., \& Older, L. (1994). Morphology and meaning in the English lexicon. Psychological Review, 101, 3-33.

MCCONKIE, G. W., \& RAYNER, K. (1975). The span of the effective stimulus during a fixation in reading. Perception \& Psychophysics, 17, 578-586.

MCCONKIE, G. W., \& ZoLA, D. (1979). Is visual information integrated across successive fixations in reading? Perception \& Psychophysics, 25, 221-224.

Morris, R. K., Rayner, K., \& Pollatse K, A. (1990). Eye movement guidance in reading: The role of parafoveal letter and space information. Journal of Experimental Psychology: Human Perception \& Performance, 16, 268-281.

Ne UfELdT, V., \& GURALniK, D. B. (1988). Webster's new world dictionary of American English: 3rd college edition. New York: Webster's New World.

Niswander, E., Pollatsek, A., \& RAyner, K. (2000). The processing of derived and inflected suffixed words during reading. Language \& Cognitive Processes, 15, 389-420.

Plaut, D. C., \& Gonnerman, L. M. (2000). Are non-semantic morphological effects incompatible with a distributed connectionist approach to lexical processing? Language \& Cognitive Processes, 15, 445-485.

PollatseK, A., HyÖNÄ, J., \& Bertram, R. (2000). The role of morphological constituents in reading Finnish compound words. Journal of Experimental Psychology: Human Perception \& Performance, 26, 820-833.

Pollatsek, A., Lesch, M., Morris, R. K., \& Rayner, K. (1992). Phonological codes are used in integrating information across saccades in word identification and reading. Journal of Experimental Psychology: Human Perception \& Performance, 18, 148-162.

Pollatse K, A., RAYNER, K., \& BALOTA, D. A. (1986). Inferences about eye movement control from the perceptual span in reading. Perception \& Psychophysics, 40, 123-130.

PRINZMETAL, W. (1990). Neon colors illuminate reading units. Journal of Experimental Psychology: Human Perception \& Performance, 16, 584-597.

Rastle, K., Davis, M. H., Marslen-Wilson, W. D., \& Tyler, L. K. (2000). Morphological and semantic effects in visual word recognition: A time course study. Language \& Cognitive Processes, 15, 507-538.

RAYNER, K. (1975). The perceptual span and peripheral cues in reading. Cognitive Psychology, 7, 65-81.

RAYNER, K. (1998). Eye movements in reading and information processing: 20 years of research. Psychological Bulletin, 124, 372-422.

Rayner, K., Balota, D. A., \& Pollatse K, A. (1986). Against parafoveal semantic preprocessing during eye fixations in reading. Canadian Journal of Psychology, 40, 473-483.

RAYNer, K., \& Bertera, J. H. (1979). Reading without a fovea. Science, 206, 468-469.

Rayner, K., Inhoff, A. W., Morrison, R., Slowiacze K, M. L., \& BERTERA, J. H. (1981). Masking of foveal and parafoveal vision during eye fixations in reading. Journal of Experimental Psychology: Human Perception \& Performance, 7, 167-179. 
RAYNER, K., MCCONKIE, G. W., \& ZOLA, D. (1980). Integrating information across eye movements. Cognitive Psychology, 12, 206-226.

RAYNER, K., \& MORRIS, R. K. (1992). Eye movement control in reading: Evidence against semantic preprocessing. Journal of Experimental Psychology: Human Perception \& Performance, 18, 163-172.

RAYNer, K., \& Pollatsek, A. (1981). Eye movement control during reading: Evidence for direct control. Quarterly Journal of Experimental Psychology, 33A, 351-373.

RAYNer, K., \& POllatse K, A. (1989). The psychology of reading. Englewood Cliffs, NJ: Prentice-Hall.

Rayner, K., Well, A. D., Pollatsek, A., \& Bertera, J. H. (1982). The availability of useful information to the right of fixation in reading. Perception \& Psychophysics, 31, 537-550.

SANDRA, D. (1990). On the representation and processing of compound words: Automatic access to constituent morphemes does not occur. Quarterly Journal of Experimental Psychology, 42A, 529-567.

SHILlcock, R. (1990). Lexical hypotheses in continuous speech. In G. T. M. Altmann (Ed.), Cognitive models of speech processing: Psycholinguistic and computational perspectives ( $\mathrm{pp}$. 24-49). Cambridge, MA: MIT Press.

Stolz, J. A., \& Feldman, L. B. (1995). The role of orthographic and semantic transparency of the base morpheme in morphological processing. In L. B. Feldman (Ed.), Morphological aspects of language processing (pp. 109-129). Hillsdale, NJ: Erlbaum.

TAFT, M. (1985). The decoding of words in lexical access: A review of the morphographic approach. In D. Besner, T. G. Waller, \& G. E. MacKinnon (Eds.), Reading research: Advances in theory and practice (Vol 5, pp. 83-124). Orlando, FL: Academic Press.

TAFT, M. (1991). Reading and the mental lexicon. Hove, U.K.: Erlbaum.

TAFT, M. (1994). Interactive-activation as a framework for understanding morphological processing. In D. Sandra \& M. Taft (Eds.), Morphological structure, lexical representation and lexical access (pp. 271-294). Hove, U.K.: Erlbaum.

TAFT, M., \& FORSTER, K. I. (1976). Lexical storage and retrieval of polymorphemic and polysyllabic words. Journal of Verbal Learning \& Verbal Behavior, 15, 607-620.
TAFT, M., \& ZHU, X. (1994). The representation of bound morphemes in the lexicon: A Chinese study. In L. Feldman (Ed.), Morphological aspects of language processing (pp. 293-316). Hillsdale, NJ: Erlbaum.

VAN JaARsveld, H. J., \& RAtTink, G. E. (1988). Frequency effects in the processing of lexicalized and novel nominal compounds. Journal of Psycholinguistic Research, 17, 447-473.

ZWITSERLOOD, P. (1994). The role of semantic transparency in the processing and representation of Dutch compounds. Language \& Cognitive Processes, 9, 341-368.

\section{NOTES}

1. Next to each morphological form category definition was an example word matching that definition. In the prefix examples, the root of the word was underlined to further highlight the differences between the two prefix types. Each definition was given a number, and the participant was told to write the appropriate number next to the word. All the participants demonstrated (verbally) that they understood all three definitions before proceeding with the rating task.

2 . Words with high-familiarity and relatively high frequency ratings were selected to ensure that the participants would (1) know the target words, (2) know the morphemes of the prefixed words, and (3) know the relationship between the morphemes and the whole word. Giraudo and Grainger (2000) have indicated that morphological facilitation can be obtained with free-stem and bound-stem words with high surface frequencies. They argued that this is particularly important in that it indicates that participants are able to make contact with morphological constituents without any conscious awareness of doing so. This was deemed important because the emphasis in the present study was to make sure all of the participants knew the target word morphemes being used to facilitate subsequent word processing in the parafovea, in order to maximize the likelihood of getting an effect.

3. A display change actually occurred in the identical condition. However, because the preview was identical to the target word, the change was not detectable (even when one searched for it).

\section{Target Word Information}

\begin{tabular}{|c|c|c|c|c|c|c|c|c|}
\hline $\begin{array}{l}\text { Pseudoprefixed } \\
\text { Word }\end{array}$ & $\begin{array}{l}\text { Word } \\
\text { Length }\end{array}$ & Frequency & $\begin{array}{l}\text { Bound-Stem } \\
\text { Prefixed Word }\end{array}$ & $\begin{array}{c}\text { Word } \\
\text { Length }\end{array}$ & Frequency & $\begin{array}{c}\text { Free-Stem } \\
\text { Prefixed Word }\end{array}$ & $\begin{array}{l}\text { Word } \\
\text { Length }\end{array}$ & Frequency \\
\hline Access & 6 & 0 & Accuse & 6 & 45 & Account & 7 & 120 \\
\hline Adopt & 5 & 71 & Admire & 6 & 32 & Adjust & 6 & 62 \\
\hline Adorn & 5 & 3 & Admit & 5 & 91 & Adverb & 6 & 3 \\
\hline Alarm & 5 & 15 & Adore & 5 & 5 & Aloud & 5 & 13 \\
\hline Adult & 5 & 1 & Align & 5 & 9 & Alone & 5 & 8 \\
\hline Aloof & 5 & 2 & Afraid & 6 & 57 & Conform & 7 & 18 \\
\hline Conquer & 7 & 10 & Alert & 5 & 25 & Dislike & 7 & 22 \\
\hline Condor & 6 & 0 & Confess & 7 & 25 & Refill & 5 & 0 \\
\hline Decal & 5 & 0 & Dispute & 7 & 37 & Alike & 5 & 6 \\
\hline Demon & 5 & 17 & Entice & 6 & 1 & Retry & 5 & 0 \\
\hline Exude & 5 & 2 & Debate & 6 & 36 & Unrest & 6 & 5 \\
\hline Demure & 6 & 3 & Immune & 6 & 0 & Insane & 6 & 13 \\
\hline Defer & 5 & 3 & Imply & 5 & 53 & Inbred & 6 & 0 \\
\hline Extinct & 7 & 1 & Dismal & 6 & 8 & Detour & 6 & 1 \\
\hline Enter & 5 & 213 & Demand & 6 & 92 & Exclaim & 7 & 20 \\
\hline Exempt & 6 & 4 & Explode & 7 & 22 & Immoral & 7 & 5 \\
\hline Exert & 5 & 29 & Excess & 6 & 19 & Enjoy & 5 & 128 \\
\hline Exist & 5 & 202 & Endow & 5 & 10 & Inland & 6 & 1 \\
\hline Exploit & 7 & 18 & Expert & 6 & 11 & Enrage & 6 & 1 \\
\hline Extra & 5 & 48 & Reply & 5 & 35 & React & 5 & 32 \\
\hline Inane & 5 & 1 & Excuse & 6 & 23 & Import & 6 & 0 \\
\hline Missile & 7 & 0 & Infect & 6 & 5 & Implant & 7 & 1 \\
\hline Protein & 7 & 35 & Innate & 6 & 13 & Unreal & 6 & 6 \\
\hline Receipt & 7 & 11 & Incline & 7 & 4 & Misuse & 6 & 2 \\
\hline
\end{tabular}


APPENDIX (Continued)

\begin{tabular}{|c|c|c|c|c|c|c|c|c|}
\hline $\begin{array}{l}\text { Pseudoprefixed } \\
\text { Word }\end{array}$ & $\begin{array}{l}\text { Word } \\
\text { Length }\end{array}$ & Frequency & $\begin{array}{c}\text { Bound-Stem } \\
\text { Prefixed Word }\end{array}$ & $\begin{array}{l}\text { Word } \\
\text { Length }\end{array}$ & Frequency & $\begin{array}{c}\text { Free-Stem } \\
\text { Prefixed Word }\end{array}$ & $\begin{array}{l}\text { Word } \\
\text { Length }\end{array}$ & Frequency \\
\hline Resist & 6 & 36 & Mishap & 6 & 4 & Profile & 7 & 18 \\
\hline Recess & 6 & 1 & Request & 7 & 54 & Review & 6 & 52 \\
\hline Regal & 5 & 2 & Repeat & 6 & 95 & Remove & 6 & 146 \\
\hline Region & 6 & 119 & Refrain & 7 & 7 & Resale & 6 & 2 \\
\hline Regret & 6 & 0 & Inept & 5 & 2 & Unfit & 5 & 1 \\
\hline Remote & 6 & 32 & Result & 6 & 329 & Return & 6 & 232 \\
\hline Relief & 6 & 66 & Export & 6 & 19 & Reform & 6 & 41 \\
\hline Uncle & 5 & 58 & Recede & 6 & 10 & Reborn & 6 & 23 \\
\hline Under & 5 & 1 & Until & 5 & 125 & Inside & 6 & 81 \\
\hline Index & 5 & 89 & Reject & 6 & 58 & Remind & 6 & 57 \\
\hline Engine & 6 & 69 & Infant & 6 & 14 & Enrich & 6 & 8 \\
\hline Disco & 5 & 0 & Excel & 5 & 2 & Repay & 5 & 10 \\
\hline Total & 203 & 1,162 & & 212 & 1,377 & & 214 & 1,138 \\
\hline Average & 5.64 & 32.28 & & 5.89 & 38.25 & & 5.94 & 31.61 \\
\hline
\end{tabular}

(Manuscript received September 13, 2002;

revision accepted for publication July 14, 2003.) 